\title{
Dupla vedação em silagem de milho na produção de bovinos confinados
}

\author{
Double seal in corn silage in confined cattle production
}

\section{Mikael Neumann ${ }^{1}$, Guilherme Fernando Mattos Leão ${ }^{2 \star}$, Leslei Caroline dos Santos ${ }^{1}$, Fabiano Marafon ${ }^{1}$ \& Eloize Jaqueline Askel ${ }^{1}$}

${ }^{1}$ Universidade Estadual do Centro Oeste, Guarapuava, PR, Brasil.

${ }^{2}$ Universidade Federal do Paraná, Curitiba, PR, Brasil. *Autor para correspondência: gfleao@hotmail.com.

Submissão: 18/05/2017 / Aceite: 30/10/2017

\begin{abstract}
RESUMO
O sucesso do sistema de produção de bovinos de corte tem como alicerce a produção de volumoso de qualidade, visto que impacta no maior ou menor desempenho produtivo dos animais e, consequentemente, no retorno econômico ao pecuarista. Nesse contexto, o objetivo do presente estudo foi avaliar o desempenho produtivo, comportamento ingestivo e características de carcaça e dos componentes não-carcaça de novilhos confinados recebendo silagem de milho submetida a dois tipos de vedação, sendo: VC - silagem de milho conservada com polietileno tipo dupla face com espessura de 110 $\mu \mathrm{m}$ (vedação convencional) e DV - silagem de milho conservada com polietileno tipo dupla face com espessura de $110 \mu \mathrm{m}$ sobreposto a outro polietileno translúcido com espessura de $110 \mu \mathrm{m}$ (dupla vedação). A determinação da relação volumoso concentrado revelou que o sistema com dupla vedação favoreceu a menor participação da fração concentrada neste tratamento $(45,4$ vs $48,3 \%)$ com consequente aumento no consumo de matéria seca diário e em relação ao peso vivo $(10,04 \mathrm{vs} 9,28 \mathrm{~kg})$, ( 2,30 vs $2,21 \%)$, respectivamente, e aumento no ganho diário de peso vivo (1,810 vs $1,565 \mathrm{~kg}$ ). Quanto a avaliação comportamental dos novilhos, aqueles que receberam silagem com sistema de dupla vedação passaram menos tempo em alimentação $\left(3,52\right.$ vs 4,60 horas dia- $\left.^{-1}\right)$ e em ruminação $(7,07$ vs 7,94 horas dia $^{-1}$ ) e mais tempo em ócio $\left(13,22\right.$ vs 11,28 horas $\left.^{-1}\right)$. Em relação as características de carcaça e os componentes não-integrantes de carcaça, não houve diferença estatística entre os tratamentos. Novilhos que receberam silagem com sistema de dupla vedação apresentaram melhor desempenho produtivo.
\end{abstract}

PALAVRAS-CHAVE: consumo, características de carcaça, avaliação comportamental, ganho médio diário.

\begin{abstract}
System production success of beef cattle is based on forage quality, since it impacts in greater or lesser way the performance and, consequently, on the economic return. In this context, the objective of the present study was to evaluate productive performance, ingestive behavior and carcass characteristics and the noncarcass components of confined steers receiving corn silage submitted to two types of sealing strategy: VC - corn silage preserved with polyethylene Double-sided with a thickness of $110 \mu \mathrm{m}$ (conventional sealing) and DV - preserved corn silage with double-sided polyethylene with a thickness of $110 \mu \mathrm{m}$ superimposed on another translucent polyethylene with a thickness of $110 \mu \mathrm{m}$ (double sealing). The determination of forage concentrate ratio revealed that the double-sealed system favored the lower participation of the concentrated fraction in this treatment ( $45.4 \mathrm{vs} 48.3 \%$ ), with a consequent increase in daily dry matter intake $(10,04 \mathrm{vs} 9.28 \mathrm{~kg})$, and in relation to live weight $(2.30 \mathrm{vs} 2.21 \%)$, and increase in average daily gain (1.810 vs $1.565 \mathrm{~kg}$ ). As for behavioral evaluation, animals receiving double-sealing system silage spent less time feeding (3.52 vs 4.60 hours day $\left.^{-1}\right)$ and rumination ( 7.07 vs 7.94 hours day $\left.^{-1}\right)$, and more leisure time (13.22 vs 11.28 hours $\left.^{-1}\right)$. Regarding the carcass characteristics and non-carcass components, there was no statistical difference between the treatments. Steers receiving silage with a double-sealed system presented better productive performance.
\end{abstract}

KEYWORDS: intake, carcass characteristics, behavioral evaluation, average daily gain. 


\section{INTRODUÇÃO}

Tradicionalmente, a planta de milho é o material mais utilizado para o processo de ensilagem, pela sua composição química preencher os requisitos para produção de silagem de qualidade (NEUMANN et al. 2014). No entanto, para que a silagem seja de qualidade, há a necessidade de explorar melhor os fatores relacionados ao processo de ensilagem, como tamanho de partícula, densidade da compactação e o tipo de material utilizado na vedação do silo (BORREANI et al. 2007, SILVA et al. 2015).

Além disso, caso a anaerobiose não seja efetiva devido a vedação insuficiente, há crescimento de microrganismos aeróbicos metabolizadores de ácido lático e compostos solúveis, promovendo a deterioração aeróbica e desenvolvimento de fungos produtores de micotoxinas (BORREANI et al. 2007, BORREANI \& TABACCO 2014, SILVA et al. 2015).

O uso adequado de uma boa vedação tem como objetivo apresentar resistência contra os raios ultravioleta, resistir a danos causados por animais ou efeitos meteorológicos e possuir barreira ao oxigênio atmosférico. As lonas utilizadas para vedação possuem espessuras diferentes, onde reflete diretamente na sua qualidade e na adequada conservação dos nutrientes solúveis do material ensilado, ao passo que o uso de vedações insatisfatórias tem como consequência interferências na qualidade da fibra e na concentração de nutrientes solúveis (FERRARETTO \& SHAVER 2015).

Estudos mostram que o nível de fibra e/ou de energia na dieta alimentar de bovinos em fase de terminação pode alterar tanto os componentes não-integrantes da carcaça como as características da carne e carcaça (SIGNORETTI et al. 1999). Fibras menos digestíveis, interferem na taxa de passagem com redução do consumo de matéria seca, promovendo maior retenção do alimento. Isso tudo reflete em alteração no comportamento do animal, dispendendo mais tempo à ruminação, com maiores gastos de energia para tal processo, o que implica em redução de produtividade, com menores resultados no ganho de peso ou produção de leite (FERRARETTO \& SHAVER 2015).

Nesse contexto, o objetivo deste estudo foi avaliar o impacto do tipo de vedação sobre o desempenho produtivo, comportamento ingestivo e características de carcaça e dos componentes não-carcaça de novilhos confinados.

\section{MATERIAL E MÉTODOS}

O experimento foi desenvolvido nas instalações do Núcleo de Produção Animal (NUPRAN), junto ao Curso de Mestrado em Agronomia do Setor de Ciências Agrárias e Ambientais da Universidade Estadual do Centro-Oeste (UNICENTRO), em Guarapuava, PR.

Os tratamentos foram compostos por: VC - silagem de milho conservada com polietileno tipo dupla face com espessura de $110 \mu \mathrm{m}$ (vedação convencional); e DV- silagem de milho conservada com polietileno tipo dupla face com espessura de $110 \mu \mathrm{m}$ sobreposto a outro polietileno translúcido com espessura de $111 \mu \mathrm{m}$ (dupla vedação).

A silagem utilizada no experimento foi confeccionada em área de 2 ha, obtida a partir do híbrido SG6418. Utilizou-se espaçamento entre linhas de $0,80 \mathrm{~m}$, profundidade de semeadura de $0,04 \mathrm{~m}$ e distribuição de 4,4 plantas $\mathrm{m}$ linear ${ }^{-1}$, totalizando população de 53.625 plantas ha- $^{-1}$, no momento da colheita. Realizouse adubação de base de $400 \mathrm{~kg} \mathrm{ha}^{-1} \mathrm{com}$ o fertilizante 08-30-20 (N-P $\left.\mathrm{O}_{5}-\mathrm{K}_{2} \mathrm{O}\right)$, seguindo Recomendações de Adubação e Calagem para os Estados de Rio Grande do Sul e Santa Catarina (CQFS-RS/SC 1995). A adubação nitrogenada de cobertura constituiu-se de $300 \mathrm{~kg} \mathrm{ha}^{-1}$ com ureia 45-00-00 (N-P $\left.\mathrm{O}_{5}-\mathrm{K}_{2} \mathrm{O}\right)$ entre estádio fenológico de V4 a V6.

A colheita das plantas foi realizada no estádio fenológico de grão farináceo, com auxílio de ensiladeira de marca Nogueira ${ }^{\circledR}$, devidamente regulada para tamanho de partícula e altura de corte das plantas em 20 $\mathrm{cm}$. Na avaliação do tamanho de partícula observou-se uma proporção de $11,56 \%$ na primeira peneira (>19 $\mathrm{mm}$ ), 47,60\% na segunda peneira (entre 8 e $19 \mathrm{~mm}$ ) e 40,85\% na terceira peneira $(<8 \mathrm{~mm})$. O material colhido foi transportado e depositado de forma homogênea em oito silos do tipo trincheira, com quatro silos para cada tratamento, localizados em local nivelado e bem drenado, com piso e paredes de concreto com dimensões de $1,5 \mathrm{~m}$ de largura, $1,0 \mathrm{~m}$ de altura e $10 \mathrm{~m}$ de comprimento. A compactação foi feita com utilização de um rolo compactador buscando compactação da massa específica entre 200 à $250 \mathrm{~kg} / \mathrm{MS} / \mathrm{m}^{3}$, posteriormente ocorreu a vedação e proteção do material ensilado conforme os tratamentos avaliados. $O$ tempo de enchimento e fechamento de cada silo variou entre 6 e 8 horas.

Utilizou-se no experimento 16 novilhos inteiros, cruza Charolês, provenientes de mesmo rebanho, com idade média de 12 meses, peso vivo médio inicial de $323 \mathrm{~kg} \pm 15 \mathrm{~kg}$. Os animais foram equilibrados por peso e condição corporal, alocados em 8 baias semicobertas, com área de $15 \mathrm{~m}^{2}$ cada baia $(2,5 \times 6,0 \mathrm{~m})$, para dois animais, com comedouro de concreto medindo 2,30 $\mathrm{m}$ de comprimento, 0,60 $\mathrm{m}$ de largura e 0,35 
$\mathrm{m}$ de altura, além de bebedouro metálico, regulado por boia automática. A limpeza das baias e instalações era realizada diariamente.

Os animais foram submetidos ao período de adaptação as instalações e à nova dieta durante 14 dias e, sequencialmente às dietas experimentais em 5 períodos de avaliação com 21 dias cada. Os animais foram pesados ao início e ao final de cada período, após jejum de sólidos de 12 horas. O manejo alimentar foi realizado duas vezes ao dia, às 6:00 e às 17:30 horas. O consumo voluntário de alimento foi registrado diariamente através da pesagem oferecida e das sobras do dia anterior e o ajuste da quantidade de alimentos foi fixada a se manter uma sobra de $5 \%$ da matéria seca oferecida em relação à consumida. $\mathrm{O}$ valor em quilosa de concentrado foi fixado onde o ajuste da dieta era realizada em relação ao volumoso. A dieta foi fornecida na forma de ração totalmente misturada (RTM), sendo constituída de silagem de milho e de concentrado comercial peletizado.

O concentrado foi constituído da mistura de milho, farelo de soja, cevada, radícula de malte, casca de soja, farelo de trigo e aveia. A composição nutricional dos alimentos utilizados nas dietas experimentais encontra-se na Tabela 1.

Foram coletadas amostras dos alimentos, das rações e das sobras semanalmente durante o período experimental. Nas amostras, analisaram-se os teores de matéria seca (MS), proteína bruta (PB), matéria mineral (MM), extrato etéreo (EE), fibra em detergente neutro (FDN) com a enzima a-amilase termo-estável, fibra em detergente ácido (FDA), cálcio (Ca) e fósforo (P) (SILVA \& QUEIROZ 2009). Os teores de nutrientes digestíveis totais (NDT) foram calculados conforme equações propostas por WEISS et al. (1992). Foi também realizada a avaliação da digestibilidade in vitro, tanto da MS quanto da FDN (TILLEY \& TERRY 1963).

As variáveis de desempenho produtivo avaliadas, durante os períodos de confinamento foram: consumo diário de matéria seca (CMSD) e por $100 \mathrm{~kg}$ de peso vivo (CMSP), ganho de peso médio diário (GMD) e conversão alimentar (CA). Para avaliação do comportamento ingestivo dos novilhos, realizou-se monitoramento de 72 horas contínuas, em dois períodos intermediários do experimento. Sendo registradas as atividades de ócio $(O)$, consumo de alimentos (CAL), consumo de água $(C A G)$ e ruminação $(R)$ a cada 3 minutos. Além disso, foi registrado através de contagens, as frequências diárias das atividades de alimentação e consumo de água, excreções de fezes e urina.

Tabela 1. Composição nutricional de silagens de milho submetidas a dois tipos de vedação e do concentrado utilizado nas dietas experimentais.

Table 1. Nutritional composition of maize silages subjected to two types of fence and concentrate used in experimental diets.

\begin{tabular}{lccc}
\hline \multirow{2}{*}{\multicolumn{1}{c}{ Composição nutricional }} & \multicolumn{2}{c}{ Silagens } & Concentrado* \\
\cline { 2 - 3 } & $\begin{array}{c}\text { Vedação } \\
\text { convencional }\end{array}$ & $\begin{array}{c}\text { Dupla } \\
\text { vedação }\end{array}$ & \\
\hline Matéria seca (\%) & 30,49 & 30,91 & 90,20 \\
Proteína bruta (\% da MS) & 6,30 & 6,20 & 19,09 \\
Fibra em detergente neutro (\% da MS) & 46,03 & 47,10 & - \\
Fibra em detergente ácido (\% da MS) & 26,97 & 28,03 & 6,43 \\
Matéria mineral (\% da MS) & 3,56 & 4,13 & 7,38 \\
Cálcio (\% da MS) & 0,16 & 0,19 & 1,20 \\
Fósforo (\% da MS) & 0,16 & 0,18 & 0,45 \\
Nutrientes digestíveis totais (\% da MS) & 68,95 & 68,21 & 83,34 \\
Digestibilidade da MS (\%) & 75,46 & 74,46 & - \\
Digestibilidade da FDN (\%) & 24,60 & 33,04 & - \\
\hline
\end{tabular}

${ }^{*}$ Monensina sódica: $40 \mathrm{mg} \mathrm{kg}^{-1}$.

Ao final do período de confinamento, após jejum de sólidos de 12 horas, os animais foram pesados e encaminhados para o frigorífico. Os abates seguiram o fluxo normal do abatedouro comercial, em conformidade com as legislações vigentes para o abate de bovinos, seguindo as normas do serviço de inspeção estadual. Nas carcaças quentes, aferiu-se o peso (PCQ) para o cálculo do rendimento em relação ao peso de fazenda e pelas carcaças frias, foram obtidos: o comprimento de carcaça, o comprimento de braço, o perímetro de braço, a espessura de coxão, e a espessura de gordura subcutânea na $12^{\mathrm{a}}$ costela (MÜLLER 1987). Também, realizou-se a pesagem dos componentes do corpo não integrantes da 
carcaça, que são: cabeça, língua, cauda, patas, couro, diafragma, coração, fígado, rins, pulmão, baço, rúmen/retículo vazios, abomaso vazio e calculou-se a porcentagem de cada componente em relação ao peso vivo.

O delineamento experimental foi o inteiramente casualizado, composto por dois tratamentos com quatro repetições, sendo cada repetição constituiu-se de dois animais integrantes da mesma baia. Os dados foram submetidos aos testes de Shapiro-Wilk e Bartlett, afim de verificar os pressupostos de normalidade e homogeneidade de variância, respectivamente. Uma vez atendidos estes pressupostos, aplicou-se o teste $\mathrm{F}$ a $5 \%$ de probabilidade de confiança, através da análise de variância (ANOVA) e em seguida o teste Tukey de comparação de múltiplas médias a $5 \%$ de significância. Os dados também foram submetidos a análise de regressão polinomial, considerando a variável dias de avaliação, por meio do procedimento "proc reg" do programa SAS INSTITUTE (1993).

\section{RESULTADOS E DISCUSSÃO}

O fornecimento da silagem com sistema de dupla vedação (dieta DV) proporcionou aumento no consumo de matéria seca $(7,56 \%)$ e também no CMSP, promovendo maior GMD (13,55\%) em relação ao sistema com vedação convencional, sem alterar $(p>0,05)$ a CA. Além disso, favoreceu a diminuição da fração concentrada na dieta, perante a relação volumoso concentrado, onde o concentrado permaneceu constante e o volumoso aumentou em decorrência do aumento no CMS (Tabela 2).

Tabela 2. Avaliação do desempenho produtivo de novilhos em terminação com silagem de milho conservada com dois tipos de vedação, e participação percentual do concentrado na dieta, conforme tratamentos.

Table 2. Evaluation of the productive performance of steers in corn silage conserved termination with two types of sealing, and percentage of participation focused on diet, as treatments.

\begin{tabular}{|c|c|c|c|c|c|c|}
\hline \multirow{2}{*}{$\begin{array}{c}\text { Silos de } \\
\text { Armazenamento }\end{array}$} & \multicolumn{5}{|c|}{ Períodos do confinamento } & \multirow[t]{2}{*}{ Média } \\
\hline & $1^{\circ}$ Período & $2^{\circ}$ Período & $3^{\circ}$ Período & $4^{\circ}$ Período & $5^{\circ}$ Período & \\
\hline & \multicolumn{6}{|c|}{ Participação da fração concentrada na dieta (\% na MS) } \\
\hline Convencional & 53,0 & 49,9 & 48,2 & 45,5 & 44,8 & $48,3 \mathrm{a}$ \\
\hline Dupla vedação & 50,2 & 47,6 & 44,9 & 43,1 & 41,1 & $45,4 \mathrm{~b}$ \\
\hline Média & 51,6 & 48,7 & 46,6 & 44,3 & 43,0 & \\
\hline \multicolumn{7}{|c|}{ Equação: \% concentrado = 53,4611 - 0,1060D (CV: 6,82\%; R²: 0,4959; $P=0,0001)^{*}$} \\
\hline & \multicolumn{6}{|c|}{ Consumo de matéria seca diário $\left(\mathrm{kg}\right.$ animal- $\left.{ }^{-1}\right)$} \\
\hline Convencional & 8,28 & 8,99 & 9,21 & 9,81 & 10,11 & $9,28 \mathrm{~b}$ \\
\hline Dupla vedação & 8,79 & 9,59 & 10,13 & 10,48 & 11,19 & $10,04 \mathrm{a}$ \\
\hline Média & 8,53 & 9,29 & 9,67 & 10,14 & 10,65 & \\
\hline \multicolumn{7}{|c|}{ Equação: $C M S D=7,7193$ + 0,0341D (CV: 8,52\%; R²: 0,5959; $P=0,0001)$} \\
\hline
\end{tabular}

\begin{tabular}{|c|c|c|c|c|c|c|}
\hline \multirow[b]{2}{*}{ Convencional } & \multicolumn{6}{|c|}{ Consumo de matéria seca em relação ao peso vivo (\%) } \\
\hline & 2,33 & 2,31 & 2,17 & 2,14 & 2,08 & $2,21 \mathrm{~b}$ \\
\hline Dupla vedação & 2,42 & 2,39 & 2,30 & 2,19 & 2,18 & $2,30 \mathrm{a}$ \\
\hline Média & 2,38 & 2,35 & 2,24 & 2,16 & 2,13 & \\
\hline \multicolumn{7}{|c|}{ Equação: CMSP = 2,2797 - 0,0014D (CV: 5,92\%; R²: 0,0894; P=0,0609) } \\
\hline & \multicolumn{6}{|c|}{ Ganho de peso médio diário $\left(\mathrm{kg}\right.$ animal $\left.{ }^{-1}\right)$} \\
\hline Convencional & 1,524 & 1,679 & 1,607 & 1,631 & 1,382 & $1,565 \mathrm{~b}$ \\
\hline Dupla vedação & 1,786 & 1,833 & 1,976 & 1,810 & 1,647 & $1,810 \mathrm{a}$ \\
\hline Média & 1,655 & 1,756 & 1,792 & 1,720 & 1,515 & \\
\hline \multicolumn{7}{|c|}{ Equação: $G M D=1,4092+0,0139 D-0,00012 D^{2}\left(C V: 19,28 \% ; R^{2}: 0,0871 ; P=0,1854\right)$} \\
\hline & \multicolumn{6}{|c|}{ Conversão alimentar $\left(\mathrm{kg} \mathrm{kg}^{-1}\right)$} \\
\hline Convencional & 5,48 & 5,42 & 5,88 & 6,15 & 7,38 & $6,06 \mathrm{a}$ \\
\hline Dupla vedação & 5,15 & 5,32 & 5,14 & 6,16 & 7,06 & $5,77 \mathrm{a}$ \\
\hline Média & 5,31 & 5,37 & 5,51 & 6,15 & 7,22 & \\
\hline
\end{tabular}

${ }^{{ }^{*} \mathrm{D}}$ = avanço do confinamento, variando de 1 a 105 dias.

Médias, na coluna, seguidas de letras minúsculas diferentes diferem entre si pelo Teste Tukey a $5 \%$. 
A menor participação percentual da fração concentrada na alimentação dos animais no sistema com dupla vedação ao longo dos períodos, comparativamente ao sistema de vedação convencional $(45,4$ vs $48,3 \%)$, respectivamente, justifica-se pelos maiores CMSD $(10,04$ vs $9,28 \mathrm{~kg})$ e CMSP $(2,30 \mathrm{vs} 2,21 \%)$ e da menor seleção da dieta. Como a oferta do concentrado foi constante durante todo período experimental para ambos os tratamentos, o aumento na proporção de silagem consumida promoveu menor valor em percentual do concentrado na dieta para o sistema de dupla vedação, tal aumento de consumo diário pode ser explicado pelas características nutricionais da silagem, que apresentou maior digestibilidade da fração fibrosa (FDN) (NEUMANN et al. 2009).

O desaparecimento mais rápido da fração FDN no rúmen está ligado ao aumento na degradação da fibra e ao aumento da taxa de passagem, reduzindo o preenchimento físico do rúmen e permitindo maior consumo voluntário (OBA \& ALLEN 2000), justificando os resultados obtidos. Além disso, no presente experimento, a maior disponibilidade de frações digestíveis do FDN na dieta DV, gerou maior aproveitamento da fração fibrosa do volumoso ofertado, que contribuiu para elevar o GMD de forma significativa e aumentar os ganhos de carcaça (Tabela 3).

Tabela 3. Efeito de dois tipos de vedação de silagem de milho sobre estimativas da carcaça de novilhos terminados em confinamento.

Table 3. Effect of two types of corn silage on fence housing estimates of steers finished in feedlots.

\begin{tabular}{lcccc}
\hline \multirow{2}{*}{ Variável } & \multicolumn{2}{c}{ Silos de armazenamento } & \multirow{2}{*}{ CV (\%) } & \multirow{2}{*}{ Valor de P } \\
\cline { 2 - 4 } & Convencional & Dupla vedação & & \\
\hline Ganho de carcaça diário $(\mathrm{kg})$ & 1,10 & 1,23 & 4,60 & 0,0397 \\
Ganho de carcaça/ganho peso vivo (\%) & 70,50 & 68,00 & 9,88 & 0,6411 \\
Ganho de carcaça total (kg) & 115,57 & 129,45 & 4,29 & 0,0336 \\
Eficiência de transformação carcaça (kg) & 12,75 & 13,34 & 11,72 & 0,6206 \\
\hline
\end{tabular}

Médias na coluna, seguidas de letras minúsculas diferentes na linha, diferem pelo teste de Tukey a 5\%.

A conversão alimentar dos animais não mostrou diferença significativa, com média de ingestão de $5,92 \mathrm{~kg}$ por $\mathrm{kg}$ de peso corporal ganho, pois, apesar do aumento no ganho de peso, o animal passou a ingerir maior quantidade de volumoso, apresentando uma proporção semelhante ao sistema de vedação convencional.

As silagens utilizadas a partir de dois tipos de vedação, além de diferenças no desempenho produtivo refletiram em modificações nos padrões comportamentais dos bovinos. Os animais alimentados com a silagem do sistema de dupla vedação despenderam menores tempos em ruminação e alimentação (Tabela 4), sendo que no sistema de vedação convencional os animais passaram 10,96\% a mais de tempo em ruminação. Isso ocorre pela maior digestibilidade de FDN do sistema com dupla vedação, no qual os animais passaram $23,48 \%$ menos tempo em alimentação (3,52 vs 4,60 horas dia $^{-1}$ ). Tal parâmetro observado no sistema com dupla vedação despendeu menor esforço na alimentação e ruminação para atingir o mesmo nível de produção do sistema com vedação convencional, considerando menor estímulo da fibra ingerida à ruminação. Tais comportamentos foram concordantes com a literatura (NEUMANN et al. 2015).

O uso de silagem com sistema de dupla vedação aumentou $(p<0,05)$ o tempo de ócio dos animais, reduziu o tempo de ruminação, as horas de alimentação e as excreções sólidas, os sem alterar os demais parâmetros avaliados.

Os resultados obtidos no presente estudo corroboram com os obtidos por OLIVEIRA et al. (2011) em dietas com inclusão de $70 \%$ de concentrado comparadas a aquelas com $40 \%$, refletiram em menor tempo em alimentação $(33,3 \%)$ e ruminação $(30,4 \%)$ e maior tempo em ócio $(26,2 \%)$. O autor aponta que esses processos fisiológicos, são sensíveis a variação de fibra na dieta, responsável por estimular a mastigação e a ruminação.

No que se refere as excreções sólidas, o sistema com dupla vedação apresentou menor frequência diária $(p<0,05)$, devido a maior capacidade de digestibilidade do alimento, sugerindo que houve maior aproveitamento da fração fibrosa da dieta fornecida.

$\mathrm{Na}$ Tabela 5 é possível verificar que as dietas experimentais compostas por silagens confeccionadas com dois tipos de vedação, produziram carcaças com características semelhantes. Porém a utilização de silagem conservada com dupla vedação gerou maior ganho de peso durante o período de confinamento, com maior peso final dos animais pré abate, apesar de não haver diferença significativa $(p>0,05)$. 
Tabela 4. Avaliação das atividades fisiológicas dos novilhos em função da dieta composta por silagens com distintos tipos de vedação, sobre frequência e número de horas ao dia, e avaliação da digestibilidade aparente das dietas.

Table 4. Evaluation of physiological activities of steers in function of the diet composed of silages with different types of fence, on frequency and number of hours a day, and evaluation of apparent digestibility of diets.

\begin{tabular}{|c|c|c|c|c|}
\hline \multirow{2}{*}{ Parâmetros } & \multicolumn{2}{|c|}{ Silos de armazenamento } & \multirow{2}{*}{ CV (\%) } & \multirow{2}{*}{ Valor de P } \\
\hline & Convencional & Dupla vedação & & \\
\hline Ruminação (horas dia-1) & $7,94^{\underline{a}}$ & $7,07 \mathrm{~b}$ & 9,52 & 0,0458 \\
\hline Ócio (horas dia-1) & $11,28 b$ & $13,22 a$ & 5,55 & 0,0007 \\
\hline Alimentação (horas dia-1) & $4,60^{\mathrm{a}}$ & $3,52 b$ & 4,38 & $<0,001$ \\
\hline Alimentação (frequência dia-1) & 26,33 & 22,66 & 16,52 & 0,1130 \\
\hline Consumo de água (frequência dia-1) & 8,83 & 9,79 & 41,18 & 0,6329 \\
\hline Excreções sólidas (frequência dia-11) & $16,20^{\mathrm{a}}$ & $12,79 b$ & 15,90 & 0,0210 \\
\hline Excreções líquidas (frequência dia ${ }^{-1}$ ) & 9,45 & 9,91 & 24,12 & 0,7056 \\
\hline Digestibilidade aparente da MS (\%) & 65,9 & 64,5 & 8,99 & 0,8512 \\
\hline
\end{tabular}

Médias na coluna, seguidas de letras minúsculas diferentes na linha, diferem pelo teste de Tukey a $5 \%$.

Tabela 5. Características da carcaça de novilhos terminados em confinamento, alimentados com silagem de milho em dois sistemas de vedação.

Table 5. Housing characteristics of steers finished in feedlots, fed on silage corn in two sealing systems.

\begin{tabular}{|c|c|c|c|c|c|}
\hline \multirow[t]{2}{*}{ Variável } & \multicolumn{2}{|c|}{ Características de carcaça } & \multirow[t]{2}{*}{ Média } & \multirow{2}{*}{$\begin{array}{l}\text { C.V. } \\
(\%)\end{array}$} & \multirow[t]{2}{*}{ Valor de $\mathrm{P}$} \\
\hline & Convencional & Dupla vedação & & & \\
\hline$\overline{P e s o}$ vivo de fazenda $(\mathrm{kg})$ & 499,6 & 528,4 & 514,0 & 3,9 & 0,0918 \\
\hline Peso de carcaça quente $(\mathrm{kg})$ & 275,7 & 286,2 & 281,0 & 5,0 & 0,3348 \\
\hline Rendimento de carcaça (\%) & 55,2 & 54,2 & 54,7 & 4,4 & 0,5516 \\
\hline Espessura de gordura (mm) & 3,9 & 3,7 & 3,8 & 19,8 & 0,8231 \\
\hline Comprimento da carcaça $(\mathrm{cm})$ & 129,5 & 127,5 & 128,5 & 3,2 & 0,6236 \\
\hline Espessura de coxão (cm) & 23,9 & 23,0 & 23,5 & 5,4 & 0,3402 \\
\hline Comprimento de braço $(\mathrm{cm})$ & 41,5 & 42,0 & 41,7 & 3,8 & 0,6704 \\
\hline Perímetro de braço $(\mathrm{cm})$ & 36,7 & 37,4 & 37,1 & 6,6 & 0,7304 \\
\hline \multicolumn{6}{|c|}{ Componentes não integrantes da carcaça (\% do peso vivo) } \\
\hline$\overline{\text { Cabeça }}$ & 2,46 & 2,46 & 2,46 & 7,3 & 0,9548 \\
\hline Língua & 0,21 & 0,19 & 0,20 & 15,3 & 0,2454 \\
\hline Cauda & 0,29 & 0,29 & 0,29 & 21,8 & 0,9567 \\
\hline Patas & 2,03 & 2,04 & 2,04 & 7,0 & 0,9248 \\
\hline Couro & 8,27 & 8,32 & 8,30 & 12,8 & 0,9516 \\
\hline Diafragma & 0,49 & 0,51 & 0,50 & 4,8 & 0,1936 \\
\hline Coração & 0,32 & 0,32 & 0,32 & 6,6 & 0,7524 \\
\hline Fígado & 1,12 & 1,07 & 1,09 & 9,6 & 0,5443 \\
\hline Rins & 0,19 & 0,19 & 0,19 & 9,9 & 0,7216 \\
\hline Pulmão & 1,45 & 1,21 & 1,33 & 14,7 & 0,1355 \\
\hline Baço & 0,34 & 0,25 & 0,29 & 16,1 & 0,0537 \\
\hline Rúmen/reticulo vazios & 1,91 & 1,70 & 1,80 & 16,9 & 0,3643 \\
\hline Abomaso vazio & 0,68 & 0,66 & 0,67 & 15,0 & 0,7373 \\
\hline
\end{tabular}

Médias na coluna, seguidas de letras minúsculas diferentes na linha, diferem pelo teste de Tukey a $5 \%$.

Para os outros parâmetros de características de carcaça (espessura de gordura, rendimento e comprimento da carcaça, espessura de coxão, comprimento e perímetro de braço) também não houve variação estatística $(p>0,05)$. Em experimento semelhante, não pode der observado diferença significativa para peso vivo de fazenda e para peso de carcaça quente, e obtiveram apenas diferenças significativas quanto ao perímetro de braço e rendimento de carcaça, em avaliação de silagens de milho em diferentes alturas de corte e tamanho de partículas (NEUMANN et al. 2008). 
Nos componentes não integrantes de carcaça não foi verificado diferenças significativas entre o sistema de vedação convencional e o de dupla vedação, e da mesma forma, não houve diferença em relação ao rendimento de carcaça, assim sugere-se que os órgãos representam a mesma proporção do corpo vazio.

Em estudo semelhante NEUMANN et al. (2008) ao avaliar o uso de silagens de milho em diferentes alturas de corte e tamanho de partículas observaram alteração no peso do rúmen-retículo, sem alteração nos demais componentes não integrantes de carcaça. Segundo esses autores o tamanho dos órgãos vitais está relacionado ao consumo de alimentos, desempenho animal e às exigências energéticas para mantença, ou seja, no que se refere aos tratamentos utilizados no presente experimento, não há condições suficientes para que mudanças bruscas entre tratamentos fossem possíveis, visto que a variância entre dietas era mínima. O nível de fibra e energia pode alterar tanto os componentes não integrantes da carcaça como as características de carne e carcaça.

\section{CONCLUSÃO}

Recomenda-se o uso de dupla vedação na conservação da silagem de milho por possibilitar maior desempenho produtivo de animais confinados.

\section{REFERÊNCIAS}

BORREANI G \& TABACCO E. 2014. Improving corn silage quality in the top layer of farm bunker silos through the use of a next-generation barrier film with high impermeability to oxygen. Journal of Dairy Science 97: 2415-2426.

BORREANI G et al. 2007. A new oxygen barrier film reduces aerobic deterioration in farm-scale corn silage. Journal of Dairy Science 90: 4701-4706.

CQFS-RS/SC. 1995. Comissão de Química e Fertilidade do Solo - RS/SC. Recomendações de adubação e calagem para os estados do Rio Grande do Sul e Santa Catarina. 3.ed. Passo Fundo: SBCS-NRS. 224p.

FERRARETTO LF \& SHAVER RD. 2015. Effects of whole-plant corn silage hybrid type on intake, digestion, ruminal fermentation, and lactation performance by dairy cows through a meta-analysis. Journal of Dairy Science 98: 26622675.

MÜLLER L. 1987. Normas para avaliação de carcaça e concurso de carcaças de novilhos. UFSM: Santa Maria. 31p.

NEUMANN M et al. 2008. Componentes de rendimento e características da carne e carcaça de novilhos confinados sob o efeito do tamanho de partícula e da altura de colheita das plantas de milho na ensilagem. Ciência Rural 38: 423-431.

NEUMANN M et al. 2009. Comportamento ingestivo e de atividades de novilhos confinados com silagens de milho de diferentes tamanhos de partícula e alturas de colheita. Ciência Animal Brasileira 10: 462-473.

NEUMANN M et al. 2014. Ensilagem: estratégias visando maior produção de leite. In: I Simpósio Brasileiro de Ruminantes Leiteiros. Anais.... Uberlândia: UFU. p.130-166.

NEUMANN $\mathrm{M}$ et al. 2015. Desempenho, digestibilidade de matéria seca e comportamento ingestivo de novilhos holandeses alimentados com diferentes dietas em confinamento. Semina: Ciências Agrárias 36: 1623-1632.

SIGNORETTI RD et al. 1999. Características quantitativas das partes do corpo não-integrantes da carcaça animal e desenvolvimento do trato gastrintestinal de bezerros da raça holandesa alimentados com dietas contendo quatro níveis de concentrado. Revista Brasileira de Zootecnia 28: 875-882.

OBA M \& ALLEN MS 2000. Effects of brown mibrib 3 mutation in corn silage on productivity of dairy cows feed two concentrations of dietary neutral detergent fiber: 1 . Feeding behavior in nutrient utilization. Journal of Dairy Science 83 : 1333-1341.

OLIVEIRA MR et al. 2011. Comportamento de novilhos confinados com silagens de milho oriundas de diferentes estádios de maturação e níveis de concentrado na dieta. Revista Brasileira de Milho e Sorgo 10: 56-65.

SAS INSTITUTE. 1993. SAS/STAT User's Guide: statistics, version 6. Cary: North Caroline. SAS Institute Inc.

SILVA MSJ et al. 2015. Production technology and quality of corn silage for feeding dairy cattle in Southern Brazil. Revista Brasileira de Zootecnia 44: 303-313.

SILVA DJ \& QUEIROZ AC. 2009. Análise de Alimentos - métodos químicos e biológicos. 3.ed. Viçosa: UFV. 235p.

TILLEY JMA \& TERRY RA. 1963. A two-stage technique for the in vitro digestion of forage crops. Grass and Forage Science 18: 104-111.

WEISS WP et al. 1992. A theoretically based model for predicting total digestible nutrient values of forages and concentrates. Animal Feed Science and Technology 39:95-110. 